\title{
Non-classical $11 \beta$-hydroxylase deficiency caused by compound heterozygous mutations: a case study and literature review
}

Dongdong Wang, Jiahui Wang, Tong Tong and Qing Yang*

\begin{abstract}
Background: $11 \beta$-hydroxylase deficiency (11OHD) is extremely rare, and reports of non-classical 11OHD are even rarer. Non-classical 110HD usually presents as premature adrenarche, hyperandrogenism, menstrual disorders, and hypertension. Because the symptoms of non-classical 110HD are mild, delayed diagnosis or misdiagnosis as polycystic ovary syndrome or primary hypertension is common.

Case presentation: This paper introduces a case of a young female patient presenting hypertension and menstrual disorders. Laboratory examination revealed increased androgen levels, mild adrenal hyperplasia, mild left ventricular hypertrophy, and mild sclerosis of the lower limb arteries. 11OHD was confirmed by genetic testing, and the patient was found to carry compound heterozygous mutations in CYP11B1 (c.583 T > C and c.1358G > A). The mutation Y195H is located in exon 3 and has not been reported previously. In silico studies indicated that this mutation may cause reduced enzymatic activity. After treatment with hydrocortisone and spironolactone, blood pressure was brought under good control, and menstruation returned to normal. We also conducted a retrospective review of previously reported cases in the literature (over 170 cases since 1991).

Conclusions: Early diagnosis of non-classical $110 \mathrm{HD}$ is difficult because its symptoms are mild. The possibility of this disease should be considered in patients with early-onset hypertension, menstrual disorders, and hyperandrogenism to provide early treatment and prevent organ damage due to hypertension and hyperandrogenism. CYP11B1 mutations are known to be race-specific and are concentrated in exons 3 and 8, of which mutations in the former are mostly associated with non-classical $11 \mathrm{OHD}$, whereas mutations in the latter are mostly found in classical 11OHD, characterized by severe loss of enzymatic activity.
\end{abstract}

Keywords: 11ß-hydroxylase deficiency, Genetic testing, Hypertension, Protein function prediction

\section{Background}

Congenital adrenal hyperplasia $(\mathrm{CAH})$ is a common genetic endocrine metabolic disorder, of which 21-hydroxylase deficiency (21OHD) is the most common type, accounting for $90-99 \%$ of all CAH cases. The second most common type of CAH is $11 \beta$-hydroxylase deficiency (11OHD), which accounts for $0.2-8 \%$ of cases [1]. Steroid 11b-hydroxylase defects lead to reduced conversion of 11-deoxycortisol (S) and 11-deoxycorticosterone (DOC) to cortisol and corticosterone, thereby leading to accumulation of the two steroid precursors mentioned above. In addition, an increase in metabolic products towards sex steroids corresponds to the typical clinical presentation including low renin hypertension, hypokalemia, hyperandrogenemia, and genital ambiguity in affected females. Current reports in the literature relevant to $11 \beta \mathrm{OHD}$ mostly involve classical 11OHD, and there are relatively few reports on non-classical $11 \mathrm{OHD}$ because of its mild symptoms.

* Correspondence: yangq@sj-hospital.org

Obstetrics and Gynecology Department of Shengjing hospital, China Medical

University, Shenyang 110001, People's Republic of China

(c) The Author(s). 2018 Open Access This article is distributed under the terms of the Creative Commons Attribution 4.0 International License (http://creativecommons.org/licenses/by/4.0/), which permits unrestricted use, distribution, and reproduction in any medium, provided you give appropriate credit to the original author(s) and the source, provide a link to the Creative Commons license, and indicate if changes were made. The Creative Commons Public Domain Dedication waiver (http://creativecommons.org/publicdomain/zero/1.0/) applies to the data made available in this article, unless otherwise stated. 


\section{Case presentation}

The patient was a 23-year-old female (46, XY karyotype) diagnosed with hypertension $(180 / 120 \mathrm{mmHg}$ ) since age 14 and a BMI of $20.8 \mathrm{~kg} / \mathrm{m}^{2}$. There was no obvious masculinization, and her parents stated that there were no obvious abnormalities in vulva development at birth. Antihypertensive drug therapy (nifedipine sustained-release tablets) had been taken continuously, and blood pressure was controlled to $130-140 / 80-90 \mathrm{mmHg}$. The patient sought treatment at our hospital due to menstrual disorders. The patient is the only child of non-consanguineous healthy parents from Northeast China. The study was approved by the ethics committees of China Medical University, and informed consent was obtained from the patient and her parents.

\section{Clinical examination and testing}

Imaging examinations included an ultrasonic cardiogram, a colour Doppler ultrasound of the carotid artery and lower limb arteries, a pelvic colour Doppler ultrasound (SSA660A, Toshiba), and a contrast-enhanced adrenal computer tomography scan (16-slice computer tomography machine, GE Lightspeed). Laboratory tests included measurements of serum potassium, natrium, testosterone, free testosterone, androstenedione, dehydroepiandrosterone sulphate, adrenocorticotropic hormone, cortisol, 17-hydroxyprogesterone, renin, and aldosterone using chemiluminescence immunoassays and biochemical assays.

\section{Genetic analysis}

Peripheral blood samples from the patient and her parents were collected for gene analysis. Direct sequencing was performed on all the exons and the exon-intron boundaries of CYP21A2 (NM_000500) and CYP11B1 (NM_000497.3).

\section{In silico analysis}

PolyPhen-2 (http://genetics.bwh.harvard.edu/pph2, Protein ID for CYP11B1 is NP_000488.3 or P15538) and SIFT/ Provean (http://sift.jcvi.org/) were used to predict whether an amino acid substitution affects protein function. The alignment in CYP11 families was performed using CYP11B1 sequences from different species and other human steroidogenic P450 cytochromes. PolyPhen-2 and DNAMAN software was used for multiple amino acid sequence alignment. CYP11B2 (PDB entry: 4DVQ.A), which shares $93.6 \%$ sequence identity with CYP11B1, was selected as the template for model building of CYP11B1. The structural representations were generated using PyMOL 2.0.6.

\section{Results}

\section{Clinical characteristics and serum hormone levels}

The patient's blood pressure at admission was 140/ $100 \mathrm{mmHg}$. The laboratory examination results are shown in Table 1. Blood potassium was normal, and androgen levels were increased. Adrenal CT indicated mild hyperplasia of both adrenal glands. Echocardiography indicated mild hypertrophy and slight enlargement of the left ventricle. Vascular ultrasound indicated mild sclerosis of the arteries in the lower limbs. Ultrasound of the uterine adnexa did not reveal any abnormality.

\section{Genetic analysis}

No mutations in CYP21A2 were found in the patient. Exons 3 and 8 of CYP11B1 harboured a compound heterozygous mutation (c.583 $\mathrm{T}>\mathrm{C}$ and c.1358G $>\mathrm{A}$ ) leading to the conversion of tyrosine at amino acid position 195 to histidine $(\mathrm{Y} 195 \mathrm{H})$ and arginine at amino acid position 453 to glutamine (R453Q) (Fig. 1a). Each parent of the patient carried one of these heterozygous mutations.

\section{Bioinformatics and in silico analysis of $\mathrm{Y} 195 \mathrm{H}$}

Homology alignments indicate that the Tyr195 residue in CYP11B1 is highly conserved among different species, but compared to other human CYP family members, it is only the same in CYP11B2 (Table 2). In silico analysis by both PolyPhen-2 and SIFT/Provean predicted a pathogenic effect of the novel mutation Y195H. The amino acid residue Y195 is localized in the E helix (Fig. 1b).

Table 1 Summary of laboratory data for the affected subject with steroid 11ß-hydroxylase deficiency

\begin{tabular}{|c|c|c|c|}
\hline \multirow[t]{2}{*}{ Parameter } & \multicolumn{2}{|l|}{ Result } & \multirow{2}{*}{$\begin{array}{l}\text { Reference } \\
\text { range }\end{array}$} \\
\hline & $\begin{array}{l}\text { Basal } \\
\text { level }\end{array}$ & $\begin{array}{l}3 \text { months after treatment } \\
\text { with hydrocortisone }\end{array}$ & \\
\hline ACTH $(p g / m l)$ & 48.9 & 16.59 & $7.2-63.3$ \\
\hline Cortisol (nomol/L) & 322 & 391 & $171-536$ \\
\hline Aldosterone (ng/ml) & 0.13 & 0.12 & $0.07-0.30$ \\
\hline Renin (ng/ml) & 0.08 & 0.44 & $0.93-6.56$ \\
\hline Serum K+ (mmol/L) & 3.64 & 4.13 & $3.50-5.30$ \\
\hline Serum $\mathrm{Na}^{+}(\mathrm{mmol} / \mathrm{L})$ & 141.2 & 139.2 & $137.0-147.0$ \\
\hline Testosterone (nmol/L) & 6.07 & 0.76 & $0.69-2.77$ \\
\hline Androstendione (nmol/L) & $>35$ & 6.8 & $2.09-10.82$ \\
\hline DHEA-S (umol/L) & 5.02 & 3.31 & $0.95-11.67$ \\
\hline Free Testosterone (pmol/L) & 42.27 & 13.24 & $0.77-33.03$ \\
\hline Estradiol (pmol/L) & 202 & - & $73.4-587$ \\
\hline Progestogen (nmol/L) & 4.67 & - & $0.64-3.6$ \\
\hline 170HP (nmol/L) & 11.6 & - & $0-30$ \\
\hline
\end{tabular}

ACTH Adrenocorticotropic Hormone, K+ Potassium, DHEA-S

Dehydroepiandrosterone sulfate, 17OHP 17-hydroxyprogesterone 


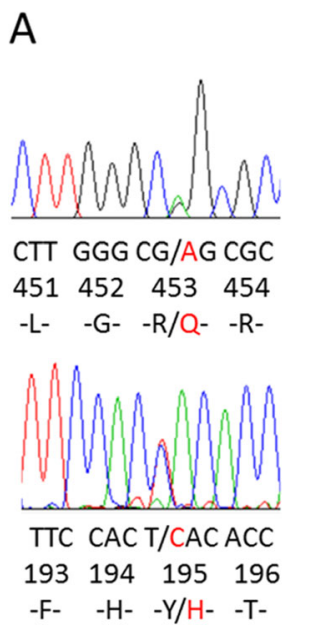

B

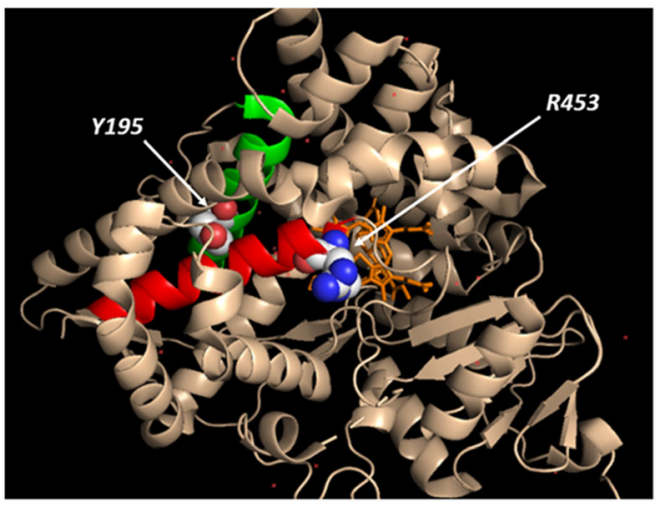

Fig. 1 CYP11B1 sequencing results and 3D molecular schematic representation of the mutation site. a Compound heterozygous mutation (c.583 T > C and c.1358G > A) that leads to the conversion of tyrosine at amino acid position 195 to histidine (Y195H) and arginine at amino acid position 453 to glutamine (R453Q). b Three-dimensional model structure of CYP11B1. Green, E helix; red, L helix. The side chains of amino acid residues Y195 (on the $E$ helix) and R453 (on the $L$ helix) are depicted

\section{Intervention and outcome}

After diagnosis of non-classical 11OHD was confirmed, the patient was given hydrocortisone twice a day (hydrocortisone $10 \mathrm{mg}$ in the morning and $5 \mathrm{mg}$ in the afternoon) and spironolactone (40 $\mathrm{mg}$ each day). Her blood pressure was brought under good control gradually $(120 / 70 \mathrm{mmHg})$, and menstruation returned to normal with decreased androgen levels (Table 1).

\section{Discussion and conclusions}

$11 \beta \mathrm{OHD}$ is an autosomal recessive genetic disease. Over 100 mutations of CYP11B1 have been reported in the literature to date. There are more homozygous than compound heterozygous mutations (69.1\% vs. $29.8 \%)$,

Table 2 Homology alignments between CYP family members

\begin{tabular}{ll}
\hline Protein ID (UniProtKB/Swiss-Prot) & Sequence framing Tyr195 \\
\hline P15538 (HUMAN CYP11B1) & TLDVQPSIFH Y TIEASNLAL \\
F7GMV0 (Macaca mulatta CYP11B1) & TLDVQPSIFH Y TIEASNLAL \\
F6XJ24 (Equus caballus (Horse) CYP11B1) & TLDARPSIFH Y TIEASNLAL \\
P51663 (Ovis aries (Sheep) CYP11B1) & TLDIAPSVFR Y TIEASTLVL \\
Q29552 (Sus scrofa (Pig) CYP11B1) & TLDIKPSIFR Y TIEASNLVL \\
P15150 (Bos taurus (Bovine) CYP11B1) & TLDIAPSVFR Y TIEASNLVL \\
Q3TG86 (Mus musculus (Mouse) CYP11B1) & SMDFQSSVFN Y TIEASHFVL \\
P15393 (Rattus norvegicus (Rat) CYP11B1) & SINIQSNMFN Y TMEASHFVI \\
P19099 (HUMAN CYP11B2) & TLDVQPSIFH Y TIEASNLAL \\
P05108 (HUMAN CYP11A1) & SGDISDDLFR F AFESITNVI \\
P05093 (HUMAN CYP17A1) & IDNLSKDSLV D LVPWLKIFP \\
P08686 (HUMAN CYP21A2) & SLLTCSIICY L TFGDKIKDD \\
P11511 (HUMAN CYP19A1) & AESLKTHLDR L EEVTNESGY \\
\hline
\end{tabular}

and there are few single heterozygous mutations (1.1\%), possibly because mutations in other exons have not yet been discovered $[2,3]$. In the past, it was believed that mutations that cause $11 \beta \mathrm{OHD}$ are mostly concentrated in exons $2,6,7$, and $8[2,4,5]$. However, our statistics revealed that most causative mutations are located in exons 3 and 8 (40\%), and that the distribution in the other exons is actually more average. Patients carrying mutations in exon 8 account for the highest proportion among all patients, and patients carrying the $\mathrm{R} 448 \mathrm{H} \mathrm{mu}-$ tation are the most numerous (Fig. 2a) [5-12]. Because the highly conserved amino acid sequence near C450 is located in exon 8, the normal structure of this region is essential for maintaining normal enzymatic activity [2]. Thus, most point mutations in exon 8 result in severe reduction of enzymatic activity, thereby resulting in classical $11 \beta O H D$. Although there are many mutations in exon 3, most cause a partial reduction in enzymatic activity and thus result in non-classical 11ßOHD (Fig. 2c) [5, 7, 13-23]. Thus, the probability of a mutation appearing in each exon is similar, but because the mutations reduce enzymatic activity to different degrees, different severities of clinical presentation are observed, and there is a high probability of misidentifying the disease for mutations in certain exons. The $\mathrm{R} 448 \mathrm{H}$ mutation and 8 other mutations are the most frequently reported and account for approximately $40 \%$ of all cases (Fig. 2b). CYP11B1 mutation shows significant race specificity. For example, the $\mathrm{R} 448 \mathrm{H}$ mutation mentioned above is common among Moroccan Jews [6]. Tunisians often carry the two mutations, G379 V and Q356X [24], of which Q356X is also common among sub-Saharan Africans and African-Americans [2, 3, 24-26]. The T318 M mutation is most common among Yemenis $[2,27,28]$, and some 


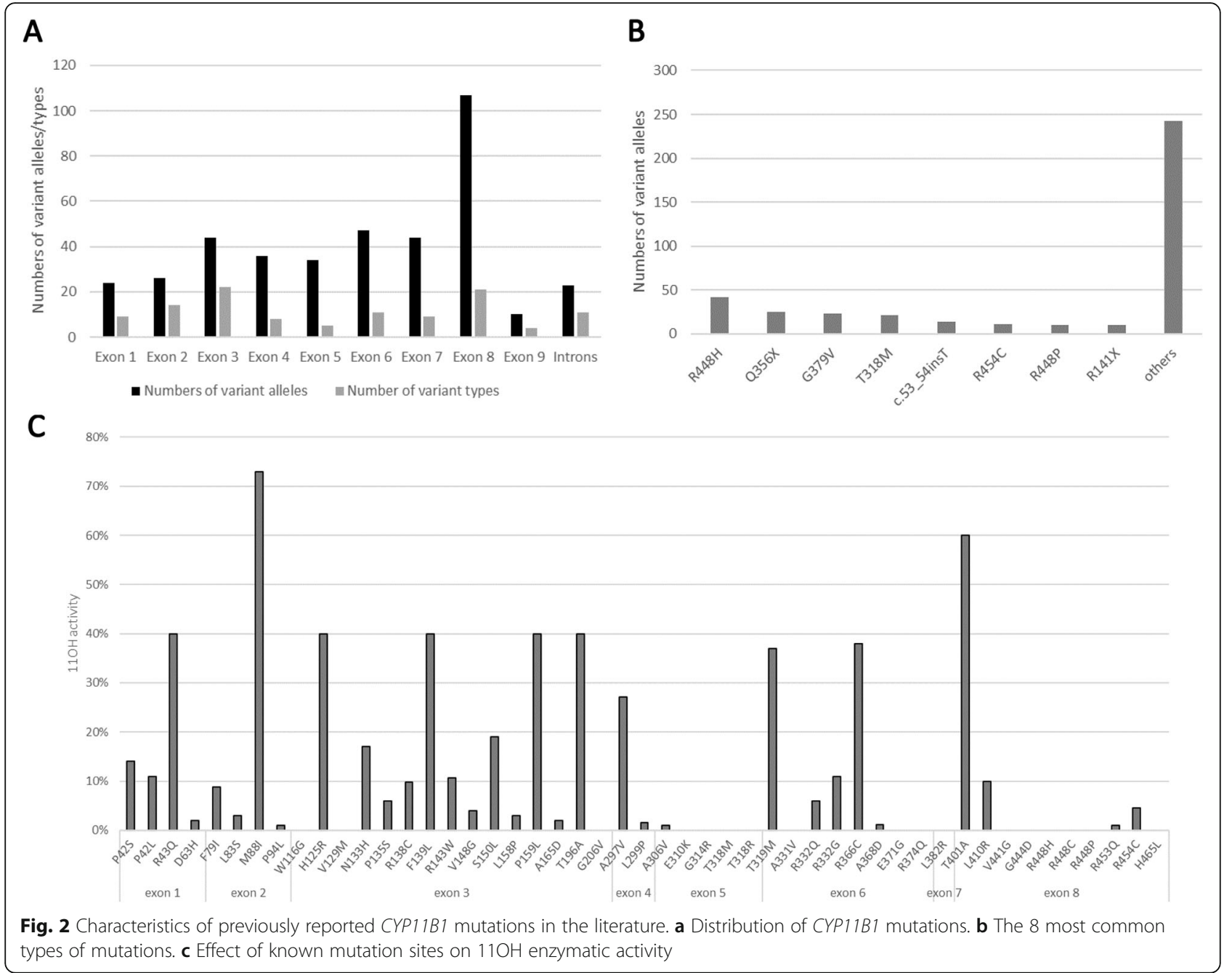

new mutations such as c.53_54insT, G206 V, W260X, R448P, and H465L are often found in Saudi Arabs [29-31]. The R454C mutation has only been reported among the Chinese $[8,10,32]$.

The case reported in this paper is a patient carrying the compound heterozygous mutations $\mathrm{Y} 195 \mathrm{H}$ and R453Q located in exons 3 and 8, respectively, which are mutation hotspots. Of these mutations, R453Q has been reported in one individual of European descent and 3 Chinese individuals [8, 23, 33], and is likely to be more common among the Chinese [33]. The residue R453 is located in the L-helix and is adjacent to the Cys-pocket motif. This domain is highly conserved in the P450 family of enzymes, and causes 11-hydroxylase activity to decrease to approximately $1 \%$ of the wild-type activity [23]. The Y195H mutation has not been reported previously. Y195 is located in the E helix. Homology alignments indicate that this amino acid sequence is relatively conserved, and predictions using PolyPhen-2 and SIFT/Provean indicate that this mutation may impair protein function. A mutation in the neighbouring amino acid T196 has been reported previously (T196A). This mutation can lead to a $30-50 \%$ loss in enzymatic activity and can result in non-classical 11OHD [15]. Three-dimensional structural models show that Y195 and T196 are located in the middle segment of the E helix and are close to L463-L464 in the L helix, which is involved in heme binding [34]. This suggests that $\mathrm{Y} 195 \mathrm{H}$ and T196A are similar and may affect enzymatic activity by indirectly affecting the structure of the $\mathrm{L}$ helix, but to a small degree; it is thus a mutation that causes non-classical $11 \mathrm{OHD}$.

Because the clinical presentation of non-classical $110 H D$ is atypical and highly variable, its prevalence may be underestimated and it may be misdiagnosed. Some patients may be misdiagnosed as having polycystic ovary syndrome because of the mildly elevated androgen levels $[13,16]$, and there are patients that only present with hypertension with mineralocorticoid features [15]. After the ACTH stimulation test, the degree of increase in 17-hydroxyprogesterone can be used to differentiate 
from non-classical 21OHD, but there is still no consensus on the diagnostic standards for non-classical 11OHD $[4,17,21]$. Baseline and stimulated 11-deoxycortisol measurements, $11 \beta$-hydroxylase activity assays, and urinary steroid profiling using LC-MS/MS are recommended to avoid missing the diagnosis of non-classical 11OHD [16, 35]. However, 11-deoxycortisol measurement and ACTH medications are currently unavailable in most Chinese hospitals, which hinders the diagnosis of 11OHD, especially non-classical $11 \mathrm{OHD}$. As the cost of genetic diagnosis decreases, genetic testing of CYP11B1 in suspected patients may make the diagnosis of non-classical 11OHD convenient and accurate.

Non-classical 11OHD patients may develop hypertension $[14,16]$, but this is highly variable, and its incidence and extent are still not clear [35]. The patient in our case developed severe hypertension at an early age, but because her diagnosis was never confirmed, antihypertensive therapy was irregular and she developed left ventricular myocardial hypertrophy and arteriosclerosis-like changes in the lower limbs, indicating the importance of early diagnosis and antihypertensive therapy. The use of mineralocorticoid receptor antagonists such as spironolactone or eplerenone for antihypertensive therapy is recommended in such patients [14]. The patient in this case was given spironolactone therapy, which controlled the blood pressure to normal.

In summary, the present study reports the case of a Chinese patient with non-classical 11OHD and presenting with early-onset hypertension, and carrying compound heterozygous mutations in CYP11B1, of which one mutation is reported for the first time. We also analysed and summarised over 170 cases that were previously reported in the literature and found that exons 3 and 8 were mutation hotspots. Mutations in exon 3 often result in non-classical 11OHD, whereas mutations in exon 8 more often result in complete loss of enzymatic activity and classical 11OHD. The possibility of non-classical 11OHD should be considered in hypertensive patients with hyperandrogenism or elevated mineralocorticoids. Such patients should be carefully identified and given an early diagnosis and treatment to avoid the adverse outcomes caused by hyperandrogenism or long-term hypertension.

\section{Availability of data and materials}

The datasets obtained and/or analyzed during the current study are available from the corresponding author on reasonable request.

\section{Authors' contributions}

DDW and JHW performed the molecular genetic studies; DDW and TT participated in the sequence alignment and drafted the manuscript. DDW participated in the sequence alignment. QY participated in the design of the study. All authors read and approved the final manuscript.

\section{Ethics approval and consent to participate}

The Hospital Ethics Committee of the Shengjing hospital of China Medical University approved the study.
Consent for publication

The patient and her family provided written informed consent for publication of their data.

\section{Competing interests}

The authors declare that they have no competing interests.

\section{Publisher's Note}

Springer Nature remains neutral with regard to jurisdictional claims in published maps and institutional affiliations.

Received: 12 May 2018 Accepted: 26 August 2018

Published online: 17 September 2018

\section{References}

1. Bulsari K, Falhammar H. Clinical perspectives in congenital adrenal hyperplasia due to 11 beta-hydroxylase deficiency. Endocrine. 2017;55(1):19-36.

2. Curnow KM, Slutsker L, Vitek J, Cole T, Speiser PW, New Ml, et al. Mutations in the CYP11B1 gene causing congenital adrenal hyperplasia and hypertension cluster in exons 6, 7, and 8. Proc Natl Acad Sci USA. 1993; 90(10):4552-6.

3. Merke DP, Tajima T, Chhabra A, Barnes K, Mancilla E, Baron J, et al. Novel CYP11B1 mutations in congenital adrenal hyperplasia due to steroid 11 beta-hydroxylase deficiency. J Clin Endocrinol Metab. 1998;83(1):270-3.

4. Nimkarn S, New MI. Steroid 11 beta- hydroxylase deficiency congenital adrenal hyperplasia. Trends Endocrinol Metab. 2008;19(3):96-9.

5. Geley S, Kapelari K, Johrer K, Peter M, Glatzl J, Vierhapper H, et al. CYP11B1 mutations causing congenital adrenal hyperplasia due to 11 betahydroxylase deficiency. J Clin Endocrinol Metab. 1996;81(8):2896-901.

6. White PC, Dupont J, New MI, Leiberman E, Hochberg Z, Rosler A. A mutation in CYP11B1 (Arg-448----his) associated with steroid 11 beta-hydroxylase deficiency in Jews of Moroccan origin. J Clin Invest. 1991;87(5):1664-7.

7. Grigorescu Sido A, Weber MM, Grigorescu Sido P, Clausmeyer S, Heinrich U, Schulze E. 21-hydroxylase and 11 beta-hydroxylase mutations in Romanian patients with classic congenital adrenal hyperplasia. J Clin Endocrinol Metab. 2005;90(10):5769-73.

8. Zhang M, Liu Y, Sun S, Zhang H, Wang W, Ning G, et al. A prevalent and three novel mutations in CYP11B1 gene identified in Chinese patients with 11-beta hydroxylase deficiency. J Steroid Biochem Mol Biol. 2013;133:25-9.

9. Dumic K, Yuen T, Grubic Z, Kusec V, Barisic I, New MI. Two novel CYP11B1 gene mutations in patients from two Croatian families with 11 beta -hydroxylase deficiency. Int J Endocrinol. 2014;2014:185974.

10. Wang X, Nie M, Lu L, Tong A, Chen S, Lu Z. Identification of seven novel CYP11B1 gene mutations in Chinese patients with 11beta-hydroxylase deficiency. Steroids. 2015;100:11-6.

11. Nguyen $\mathrm{HH}$, Eiden-Plach A, Hannemann F, Malunowicz EM, Hartmann MF, Wudy SA, et al. Phenotypic, metabolic, and molecular genetic characterization of six patients with congenital adrenal hyperplasia caused by novel mutations in the CYP11B1 gene. J Steroid Biochem Mol Biol. 2016; 155(Pt A):126-34.

12. Yurekli BS, Kutbay NO, Onay H, Simsir IY, Kocabas GU, Erdogan M, et al. A novel CYP11B1 mutation in a Turkish patient with 11 beta-hydroxylase deficiency: an association with the severe hypokalemia leading to rhabdomyolysis. Hormones (Athens, Greece). 2016;15(2):300-2.

13. Joehrer K, Geley S, Strasser-Wozak EM, Azziz R, Wollmann HA, Schmitt K, et al. CYP11B1 mutations causing non-classic adrenal hyperplasia due to 11 beta-hydroxylase deficiency. Hum Mol Genet. 1997;6(11):1829-34.

14. Mooij CF, Parajes S, Rose IT, Taylor AE, Bayraktaroglu T, Wass JA, et al. Characterization of the molecular genetic pathology in patients with 11 beta-hydroxylase deficiency. Clin Endocrinol. 2015;83(5):629-35.

15. Barr M, Mackenzie SM, Wilkinson DM, Holloway CD, Friel EC, Miller S, et al. Functional effects of genetic variants in the 11 beta-hydroxylase (CYP11B1) gene. Clin Endocrinol. 2006;65(6):816-25.

16. Reisch N, Hogler W, Parajes S, Rose IT, Dhir V, Gotzinger J, et al. A diagnosis not to be missed: nonclassic steroid 11beta-hydroxylase deficiency presenting with premature adrenarche and hirsutism. J Clin Endocrinol Metab. 2013;98(10):E1620-5.

17. Parajes S, Loidi L, Reisch N, Dhir V, Rose IT, Hampel R, et al. Functional consequences of seven novel mutations in the CYP11B1 gene: four mutations associated with nonclassic and three mutations causing classic 11\{beta\}-hydroxylase deficiency. J Clin Endocrinol Metab. 2010;95(2):779-88. 
18. Krone N, Grischuk Y, Muller M, Volk RE, Grotzinger J, Holterhus PM, et al. Analyzing the functional and structural consequences of two point mutations (P94L and A368D) in the CYP11B1 gene causing congenital adrenal hyperplasia resulting from 11-hydroxylase deficiency. J Clin Endocrinol Metab. 2006;91(7):2682-8.

19. Menabo S, Polat S, Baldazzi L, Kulle AE, Holterhus PM, Grotzinger J, et al. Congenital adrenal hyperplasia due to 11-beta-hydroxylase deficiency: functional consequences of four CYP11B1 mutations. Eur J Hum Genet: EJHG. 2014;22(5):610-6.

20. Krone N, Riepe FG, Gotze D, Korsch E, Rister M, Commentz J, et al. Congenital adrenal hyperplasia due to 11-hydroxylase deficiency: functional characterization of two novel point mutations and a three-base pair deletion in the CYP11B1 gene. J Clin Endocrinol Metab. 2005;90(6):3724-30.

21. Riedl S, Nguyen HH, Clausmeyer S, Schulze E, Waldhauser F, Bernhardt R. A homozygous L299P mutation in the CYP11B1 gene leads to complete virilization in 46,XX individuals with 11-beta-hydroxylase deficiency. Horm Res. 2008;70(3):145-9.

22. Kuribayashi I, Nomoto S, Massa G, Oostdijk W, Wit JM, Wolffenbuttel BH, et al. Steroid 11-beta-hydroxylase deficiency caused by compound heterozygosity for a novel mutation, p.G314R, in one CYP11B1 allele, and a chimeric CYP11B2/CYP11B1 in the other allele. Horm Res. 2005;63(6):284-93.

23. Krone N, Grotzinger J, Holterhus PM, Sippell WG, Schwarz HP, Riepe FG. Congenital adrenal hyperplasia due to 11-hydroxylase deficiency-insights from two novel CYP11B1 mutations (p.M92X, p.R453Q). Horm Res. 2009; 72(5):281-6.

24. Kharrat M, Trabelsi S, Chaabouni M, Maazoul F, Kraoua L, Ben Jemaa L, et al. Only two mutations detected in 15 Tunisian patients with 11 betahydroxylase deficiency: the p.Q356X and the novel p.G379V. Clin Genet. 2010;78(4):398-401.

25. Skinner CA, Rumsby G, Honour JW. Single strand conformation polymorphism (SSCP) analysis for the detection of mutations in the CYP11B1 gene. J Clin Endocrinol Metab. 1996;81(6):2389-93.

26. Andrew M, Barr M, Davies E, Wallace AM, Connell JM, Ahmed SF. Congenital adrenal hyperplasia in a Nigerian child with a novel compound heterozygote mutation in CYP11B1. Clin Endocrinol. 2007:66(4):602-3.

27. Cerame BI, Newfield RS, Pascoe L, Curnow KM, Nimkarn S, Roe TF, et al. Prenatal diagnosis and treatment of 11 beta-hydroxylase deficiency congenital adrenal hyperplasia resulting in normal female genitalia. J Clin Endocrinol Metab. 1999:84(9):3129-34.

28. Motaghedi R, Betensky BP, Slowinska B, Cerame B, Cabrer M, New Ml, et al. Update on the prenatal diagnosis and treatment of congenital adrenal hyperplasia due to 11 beta-hydroxylase deficiency. J Pediatr Endocrinol Metab : JPEM. 2005;18(2):133-42.

29. Bin-Abbas B, Al-Humaida D, Al-Sagheir A, Qasem E, Almohanna M, Alzahran AS. Divergent gender identity in three siblings with 46XX karyotype and severely virilizing congenital adrenal hyperplasia caused by a novel CYP11B1 mutation. Endocr Pract: J Am Coll Endocrinol Am Assoc Clin Endocrinol. 2014:20(10):e191-7.

30. Alqahtani MA, Shati AA, Zou M, Alsuheel AM, Alhayani AA, Al-Qahtani SM, et al. A novel mutation in the CYP11B1 gene causes steroid 11 betahydroxylase deficient congenital adrenal hyperplasia with reversible cardiomyopathy. Int J Endocrinol. 2015;2015:595164.

31. Alzahrani AS, Alswailem M, Murugan AK, Al-Humaida D, Capper CP, Auchus RJ, et al. A high rate of novel CYP11B1 mutations in Saudi Arabia. J Steroid Biochem Mol Biol. 2017;174:217-24.

32. Wu C, Zhou Q, Wan L, Ni L, Zheng C, Qian Y, et al. Novel homozygous p. R454C mutation in the CYP11B1 gene leads to 11beta-hydroxylase deficiency in a Chinese patient. Fertil Steril. 2011;95(3):1122.e3-6.

33. Gu C, Tan H, Yang J, Lu Y, Ma Y. Congenital adrenal hyperplasia due to 11 hydroxylase deficiency-compound heterozygous mutations of a prevalent and two novel CYP11B1 mutations. Gene. 2017:626:89-94.

34. Otyepka M, Skopalik J, Anzenbacherova E, Anzenbacher P. What common structural features and variations of mammalian P450s are known to date? Biochim Biophys Acta. 2007;1770(3):376-89.

35. Escobar-Morreale HF, Carmina E, Dewailly D, Gambineri A, Kelestimur F, Moghetti P, et al. Epidemiology, diagnosis and management of hirsutism: a consensus statement by the androgen excess and polycystic ovary syndrome society. Hum Reprod Update. 2012;18(2):146-70.

\section{Ready to submit your research? Choose BMC and benefit from:}

- fast, convenient online submission

- thorough peer review by experienced researchers in your field

- rapid publication on acceptance

- support for research data, including large and complex data types

- gold Open Access which fosters wider collaboration and increased citations

- maximum visibility for your research: over $100 \mathrm{M}$ website views per year

At BMC, research is always in progress.

Learn more biomedcentral.com/submissions 